\title{
The experience of implementing the Intercollegiate Educational Robotics Olympiad within the framework of the Training of Trainers in Vulnerable Areas Project in Costa Rica
}

\author{
Pedro Fonseca Solano \\ Universidad Nacional de Costa Rica, Escuela de Informática \\ Heredia, Costa Rica, 20601 \\ pedro.fonseca.solano@una.cr \\ and \\ Irene Hernández Ruiz \\ Universidad Nacional de Costa Rica, Escuela de Informática \\ Heredia, Costa Rica, 40205 \\ irene.hernandez.ruiz@una.cr
}

\begin{abstract}
This article presents the experience of conducting the Intercollegiate Robotics Olympiad in 2017, as a result of the implementation of the project of the School of Computing of the National University of Costa Rica (UNA), called Trainers in Robotics for Colleges in Vulnerable Areas, which is developed jointly with the Costa Rican Institute of Drugs (ICD) and the Ministry of Public Education (MEP). In addition, the challenges developed by the executors of the project and the results obtained by the benefited students who participated in this event are announced. This is an inter-institutional project of Costa Rica, which is aimed at preparing instructors in the area of robotics at the secondary level, so that they can train their students in vulnerable regions of Costa Rica. In order to give their students the opportunity to occupy their free time in positive activities.
\end{abstract}

Keywords: competition, challenges, drug prevention, LEGO EV3, Robotics

\section{Introduction}

At the end of 2015, the "Training of Trainers in Robotics for Colleges in Vulnerable Areas of Costa Rica Project" was developed jointly by the School of Computing of the National University of Costa Rica (UNA), with the Costa Rican Institute of Drugs (ICD) and the Ministry of Public Education (MEP). Which seeks the training of secondary teachers in the area of educational robotics. Giving priority attention to reinforce the importance of the teacher and its role as mediator, to generate changes in the students, which implies greater effort on the part of the professors, this effort is also manifested in the form that the training is given, since it develops intensively with sessions of eight hours a day all week long. Students share knowledge, friendship, the desire to be better people, facing fears and realities of our educational system, but in a positive and stimulating environment where each participant is important and each work pair represents a good change for their institution. We also work on transversal axes on prevention, which ultimately through specific protocols attacking the problem of drug addiction, making them see that drugs take them away from learning opportunities like this, showing that schools have recreational activities and that students who are not in school, miss the great opportunity to have fun learning and experiment with problem solving using robots, and the art of designing, building and programming a robot.

Through workshops, we intentionally try not to be like a traditional class, the idea is to create a positive environment of respect, camaraderie, sharing knowledge, and that participants learn at their own pace and style, under basic coexistence rules [1]. 
In addition, the project focuses on the attention of young people who are in areas of social risk or vulnerability, who are advised by the ICD and the MEP, by using robots as a mean to attract their attention we try to stimulate them to approach the use of technology as creators more than as consumers.

On the other hand, UNICEF estimates that between 25 and 32\% of the young population between 12 and 24 years old suffer the consequences of at least one type of risky behavior such as dropping out of school, adolescent motherhood, unemployment, drug addiction, or conflicts with the law [2].

A competition must have mechanisms to focus participants' attention on the process and not on the result. If the process is the center of attention, you will find it justified to focus on the quality of the process and learning. This approach is only possible when the environment favors it.

In summary, the most beneficial and healthy competitions are those that have a symbolic reward, are short and pleasant, allow all participants to perceive that they are winning, and that add value to the process and the quality of the work rather than to the win win result [3].

From the educational robotics is established, from Piaget's constructivist theory, that there is no learning if there is no intervention of the student in the construction of the object of knowledge [4].

The motivation and attitude for learning, that is, adaptation to changes according to the task, are key in order to turn children into competent people in the future [5].

Extracurricular activities are usually more relaxed, allow deviations and therefore, are easier to configure and organize. There are several examples of the use of curricular educational robotics in formal settings [6]. It has been shown that Mindstorm robots teach a wide range of subjects ranging from language [7], physics [8] and robotics [9].

Some examples of robotic Olympiads that have been made are: in Bolivia for the year 2015, the Ministry of Education through the Vice-Ministry of Science and Technology officially launches the Call for the second version of the Bolivian Robotics Olympiad (OBR), with three participation categories: Category A in which the work material is the Lego robotics kit in its NXT or EV3 models that allows the participants to concentrate on the programming of the robot [10]. Another international competition is the First Lego League (FLL) in which young people from 6 to 16 years old propose solutions to a challenge from the real world. The first edition took place in 1999 and currently more than 230,000 young people from 65 different countries participate [11]. In addition, the WRO Olympiad, which takes place annually in several countries with local competitions and finally the participation of the winners in the World Cup, which takes place in a WRO member[12].

In 2010, the School of Computer Science organized the National Robotics Olympiad in which 500 students divided into 125 teams participated with the participation of young people, in order to develop skills and knowledge in them.to identify problems, and solve them in the best way and design solutions to them using available technology or developing a new one [13].

On the other hand, this project considers from the beginning the importance of incorporating more women teachers in the project and in the field of educational robotics, achieving by 2016 a total population of 48 teachers of which 26 are women. In this same line for the year 2016 a survey was conducted on a sample of students aged between 13 and 16 years corresponding to all levels of secondary school, and it was found that the impact that the knowledge of robotics has had on young females have motivated them.at a general level. They all considered that having learned robotics has been useful for them to learn to program. On the other hand, $90 \%$ of female students have gotten motivated to study a career related to computer science [14].

Unfortunately the Latin American continent doesn't have enough professionals to be a power in the development of software or technology in general, so it is important to encourage children and young people either with workshops or courses incorporated in their own houses of study (these being those who can grow the technological development having a direct consequence on the economic and social growth of their country) with this idea we start creating the future now [15]. It is for this reason that one of the objectives of the project is to consider motivating students in the study of programming so that they can visualize the opportunities they may have in the long term.

The article is organized as follows. In section II the description of the Olympiad, in section III the participating population, in section IV established categories, in section V Quantity of equipment versus categories, in section VI assessment instrument and results, in section VII recommendations and finally in section VIII conclusions.

\section{Description of the Olympiad}

The purpose of this Olympiad is that students can share among the participants and test the knowledge obtained in the workshops, through challenges that have been designed so that students can effectively solve them in an appropriate time and with a level of complexity according to what was learned. There are 
configurations in the challenges that can vary at the moment of the Olympiad, which means that the level can increase at the moment, not everything they bring is $100 \%$ ready.

For the development of this Olympiad the 36 schools trained so far were invited and 5 challenges were previously elaborated so that the beneficiary students will participate in the construction and programming of models using the LEGO EV3 KIT during the day of the Olympiad.

The Educational Kit 45554, is composed of electronic parts: Brick that has 8 ports, 4 for sensors and 4 for engines, in addition to 3 engines, 2 large and one medium. Sensors, 2 touch, 1 ultrasound, compas movement, and a set of parts, beams, axes, connectors, pins, rims, tires among others, which allow to create a series of practically unlimited models.

Because Lego, we can say alot about the Lego and its "power" for boys and girls to develop their mathematical logical thinking, it allows them to increase their reasoning capacity, even though it has not been proven, however, what we do know is the high level of motivation that causes it, which allows students to solve problems in a much more enjoyable way than traditional classes or laboratories. Although the price may be privative for many, there is also the virtual environment, which allows to design, schedule and execute tasks. In fact in the project the digital designer Lego (LDD), as a support tool.

This activity was developed during a whole day in one of the beneficiary schools, allowing students to show their skills and skills acquired in the area of robotics, thanks to the training work of teachers, who have transmitted the basic knowledge to solve problems using challenges in which robots type EV3 are used.

Prior to the competition, the project provided the tables, which were designed for the activity, thus achieving that all the challenges will be developed simultaneously and that the participants also manage to share with teams from other institutions that are beneficiaries of the project.

For this activity a website named National Meeting of Robotics for Colleges in Vulnerable Areas in Costa Rica was set up, two months before the competition with information on the 5 categories and their regulations, general guidelines, news and other details of the Olympiad, so that the participants had the same information about the challenges and regulations, the link used and which is currently active is: https://pfonsecalice.jimdo.com.

In addition, a strategy was developed within the framework of the project, to generate an enrollment process by the teachers, since the participation of the students should be ensured and they should have the permits for that day.

Before the start of the competition, there was the participation of judges who were previously selected by the executors of the project, who already had experiences in this type of competences. And the participation of two judges for the five categories was achieved, for a total of 10 judges. For their participation, 3 meetings were held to analyze aspects such as: construction model, the role of the beneficiary students, established rules, regulations to solve conflicts, tests previously carried out, and clarification of questions and doubts. Having previously a set of trained judges is paramount, since it makes it possible to guarantee that the competition is carried out in an orderly, fair manner and does not generate conflicts during the competition or simultaneously.

Prior to the start of each competition, the judges grouped the students participating in the groups according to their category and ensured that each participating group complied with the previously published regulations and that fair competition was achieved. This factor is essential as part of one of the objectives of the project, since when using the LEGO EV3 technology it is given as a tool to generate motivation in the study of programming and information and communication technology; and an error or unnecessary conflict can have an impact on the learning and the negative experience in the students, this aspect is treated with the transversal axes, with the theme "Skills for life".

Before the end of the Olympiad, the participating students were asked to complete a prior evaluation survey to analyze the experience they had in this activity. Abarca (1995) refers to motivation as a phenomenon composed of several components, which appear and disappear according to the circumstances determined by social, cultural and economic phenomena and, therefore, must have a particular treatment for each one of them. the subjects [16].

In a study conducted by McWhorter in two sections of the CS1 course at Texas A \& M University indicated in their results that the use of LEGO had little or no effect on the student and rather motivation is measured by motivated strategies for learning [17]. In this way, the project team has considered it essential to develop a series of strategies with the secondary teachers to carry out more practice and to see the theory little by little, and rather to apply it during the activities in class. In this way, teachers apply these strategies with their students. In section 5, the results obtained from the evaluation are explained in detail.

On the other hand, it is very important that thanks to the ICD, UNA and MEP, financial support was obtained for the generation of trophies and medals and, in general, for the Project. The first three places in each of the categories were awarded, as well as all the participants who competed in this activity. 


\section{Participating Population}

Although all the schools were invited to participate in this first Project Olympiad, only 25 managed to participate, which represents $69.44 \%$ of the beneficiary school population. The follow-up to the schools that did not manage to participate was due to different situations, including their own activities within the school, for rescheduling exams and the same meeting due to a strong tropical storm that affected the country at that time and left several institutions with serious problems in physical and road infrastructure.

With the 25 participating schools, it was possible to have 202 high school students between the ages of 13 and 17, of whom 56 were women, representing 28\% and 146 men, which corresponds to $72 \%$. Fig. 1 shows the percentages of participation by gender.

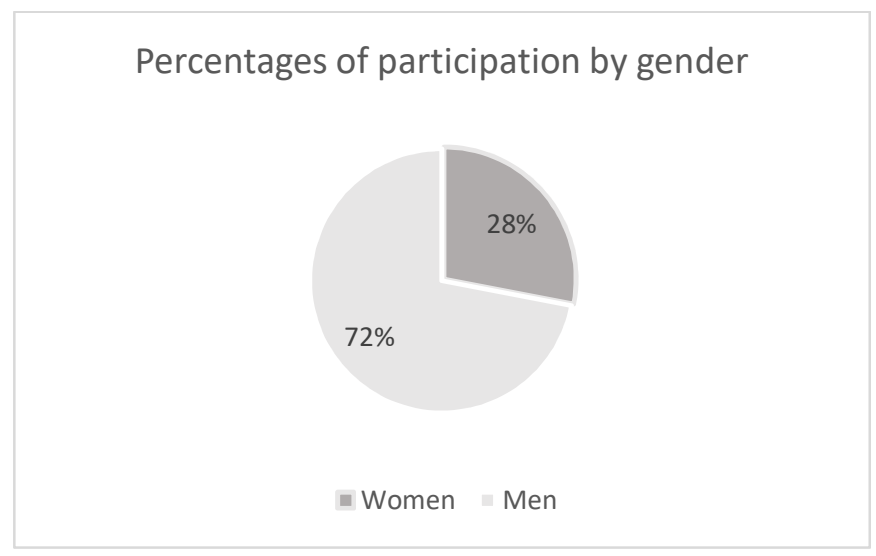

Figure 1: percentages of participation by gender.

\section{Established Categories}

For this Olympiad, the executors of the project, developed the 5 categories of competence, allowing students to apply the knowledge learned during the lessons with their teachers. Below, each of the challenges developed is described:

\subsection{Regular Category}

This challenge seeks that all participants have found out how to program a line follower, in addition to using the ultrasound sensor to detect an obstacle and a third (medium) motor to remove the obstacle from the road.

For category was established a circuit or route, in which the robots had to complete the route (follower of lines), leaving a point and reaching a goal, the route would appear 6 obstacles (plastic cups of 16 ounces) that were placed in specific places of the circuit and that the robot should move from its path and from the area where the obstacle is placed. Fig. 2 shows a graphic representation of the track used in this type of challenge.

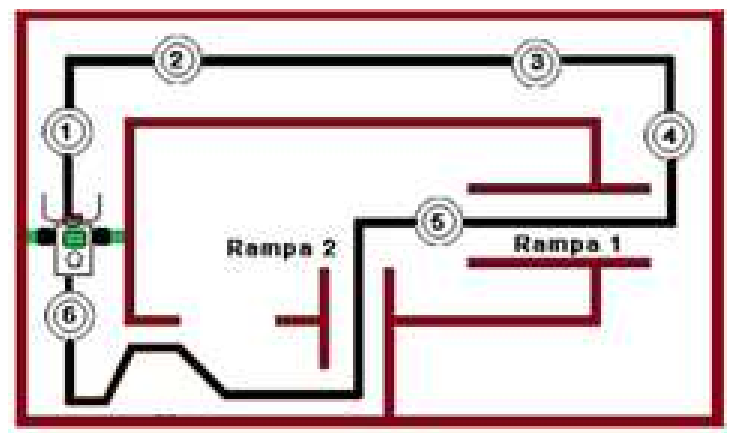

Figure 2: Pista de la Competencia Regular 


\section{2 Football Category IV}

It was a football match between 4 robots, each robot used a strategy for defense and attack, could also use others that did not attack the integrity of another robot or himself.

In this category, the team of robots that scores the most goals in a 3-minute game divided into two 1.5minute times wins. Fig. 3 shows a graphic representation of the track used in this type of challenge, the black rectangle in the area where the robots could circulate and during the game you could use more than one ball (foam or stereophone). While the black line limits the rectangular area where robots can circulate.

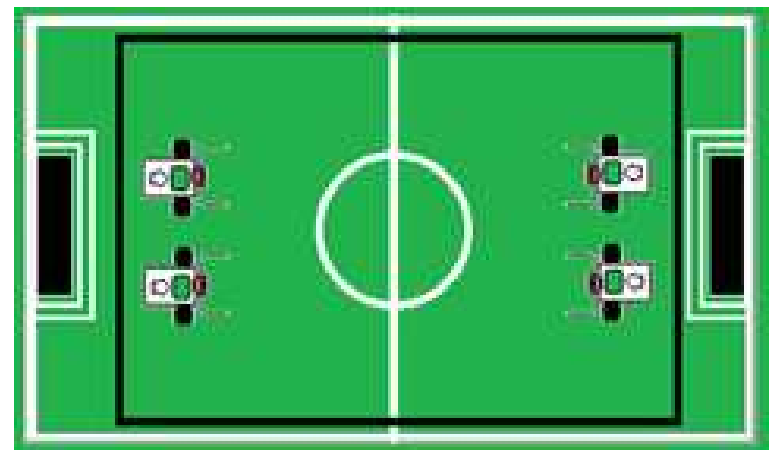

Figure 3: Football Competition Track

\section{3 Medieval Justas category}

This challenge consisted in a competition between groups of 10 robots (using a disguise that represents a horse and a knight with their respective shield and spear). Five robots were distributed on each side, according to a previously drawn random raffle from 1 to 10 . The spear that made up the disguise was used to touch the shields and take lives from the robots. Each robot had 5 lives (verifiable by judges at any time before and during the competition), the winner was the robot that was left alive after the others had stopped.

As the robots stopped, they were removed from the competition area. The winner and the robot that had the best disguise were awarded.

\section{4 Apps Category}

This challenge consisted of using the app that was developed in the project [18] Fig. 4 shows an image of the developed App.

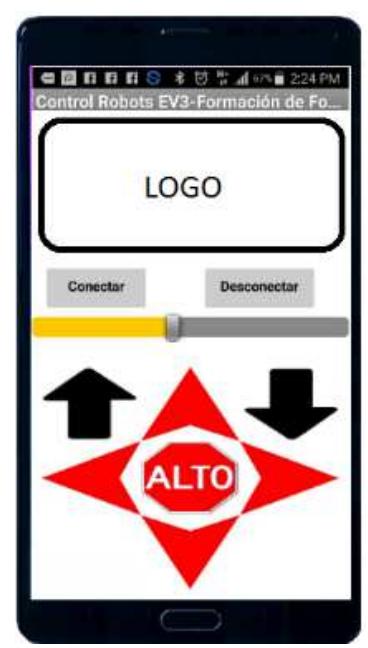

Figure 4: Image of the APP used 
This app allows moving a robot model to the right, left, front and back, which was designed with APP INVENTOR, a visual programming language developed by the Massachusetts Institute of Technology (MIT) Media Lab. In this way, with the App was developed a challenge whose objective was to control the robot avoiding the obstacles (plastic cups of 16 ounces), the idea was to promote respect for values, each antivalent (-) must be overcome and not "hit" dodging, the idea was to disguise the glasses with material alluding to an antivalent. In the case of a value or a positive behavior $(+)$, rather it should be grouped all the vessels is its corresponding place, the controller of the robot had to move the vessels according to the configuration to reach the goal. The participants brought their own values and anti-values and in the tournament they are exchanged. Three possible configurations of this challenge were developed and the judges could make random changes to their configuration. Fig. 5, 6 and 7 show a graphic representation of the track used in this type of challenge.

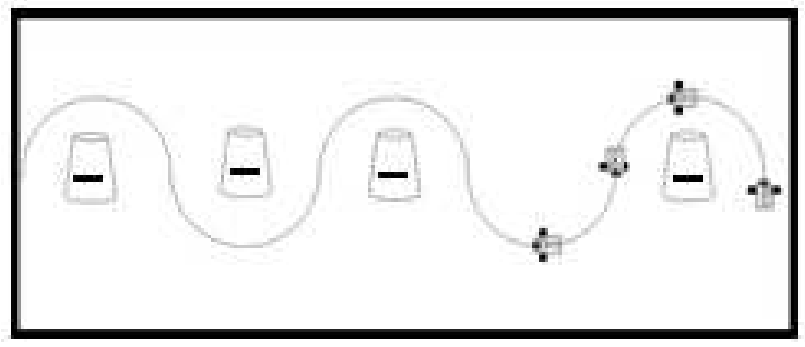

Figure 5: Tour of the App where only antivalores should be avoided

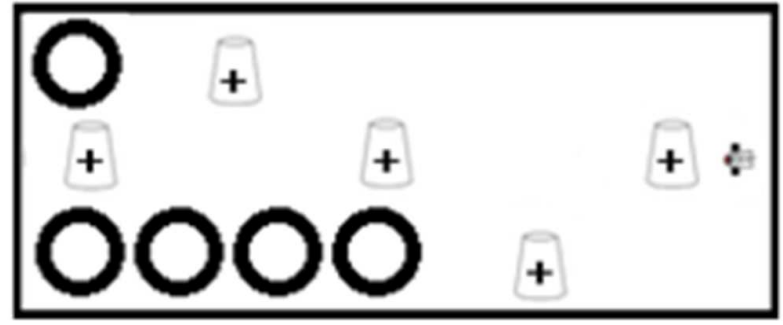

Figure 6: Tour of the App where the values are grouped in established places

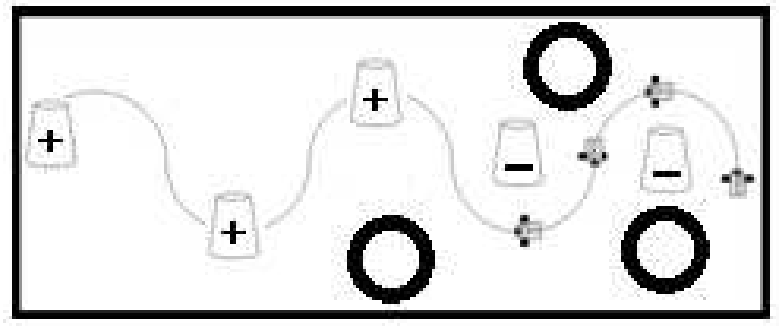

Figure 7: Tour of the App in combination where antivalores are avoided and values are grouped

\subsection{Open}

This was an open category and the teams presented a project or work done in their institution, in order to be innovative in two areas: first, an innovation in the way of solving a problem in which robotics is used as medium, and is open to any positive and decorous subject. Second: a positive change in a person (s) or group and that has caused an impact so it is considered important to share it. There was 10 minutes for presentation to the public and jury using the resources they considered necessary.

It is worth mentioning that this type of challenges is extremely significant, because it has to do precisely with the objectives of the project, what we seek is to generate changes through the conviction that there are opportunities even in our educational institutions, by teachers who look for alternatives to generate 
opportunities to our students, which allows them to live the importance of studying and doing positive things in their free time or that intentionally the institution through these workshops generates this type of spaces such as clubs or workshops.

In this category, 6 students were rewarded for their success cases, since they were students with a problematic profile, with little interest in the study, there were no classes and through the project they changed their way of proceeding. The opportunity that the project offered them, they took it positively.

\section{Quantity of equipment versus categories}

The number of teams according to the category of participation in the Olympiad were:

Table 1: Quantity of teams versus categories

\begin{tabular}{cc}
\hline Category & Quantity of teams \\
\hline Regular & 15 \\
Soccer IV & 5 \\
Medieval Justas & 23 \\
Apps & 12 \\
Open & 6 \\
Registered Teams & 61 \\
\hline
\end{tabular}

In Figure 6, it can be seen that, the category with the highest participation record was that of Medieval Justas $23(37.70 \%)$, since it is a game in which the robot that is in motion wins, and the level of complexity is medium, in addition to generating great enthusiasm to disguise the robot and make it an environment. Football 5 teams (9.84\%), more competitors were expected to be the predominant sport, however for these generations, it seems that it is not so important. The Regular, with 15 teams (24.6\%), the level of complexity is greater and the robot is autonomous. In the case of Apps, 12 teams $(19.7 \%)$, it is more complex to control via cell phone and is played in pairs. And finally the open with 6 participants $8(8.20 \%)$.

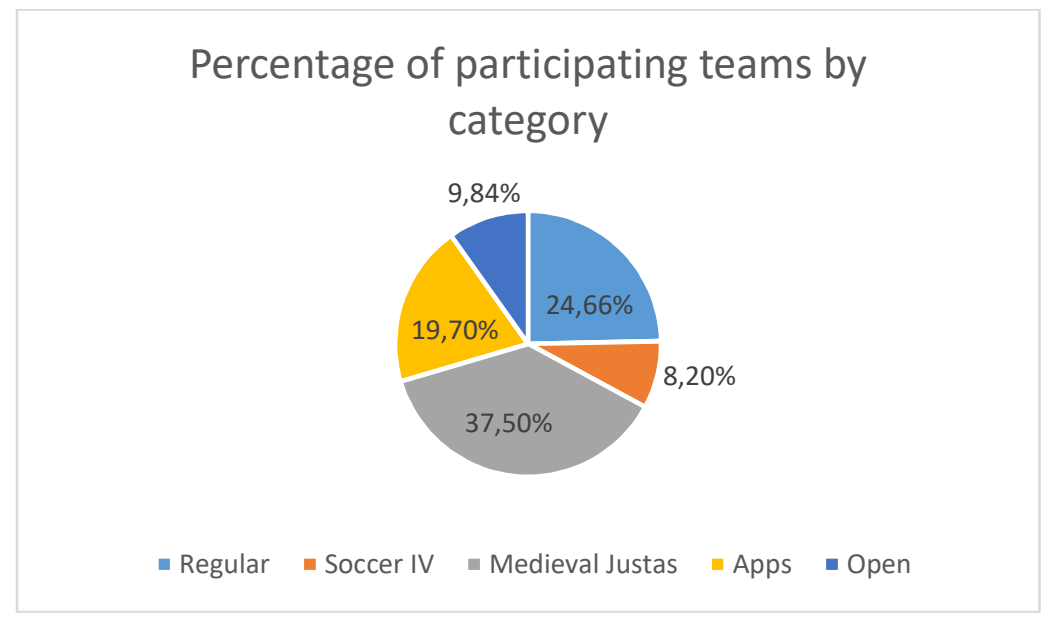

Figure 6: Percentage of teams by category

\section{Instrument for evaluation and results}

A sample of the students was asked to answer an evaluation tool about the Olympiad and how they felt in the competition. For which there were 76 responses of which, 17 were women which corresponds to $28.94 \%$ of the population and 59 were men, corresponding to $71.06 \%$

The applied evaluation instrument included the following questions:

- They liked to compete in this Olympiad, $100 \%$ of the population said yes.

- In 2017, in how many workshops he has participated. In this question the women responded that on average in 4 workshops and men in 3 workshops.

- What emotions and feelings have you experienced through robotics? 
Table 2: Frequencies of responses of experienced feelings

\begin{tabular}{cccccc}
\hline \multicolumn{6}{c}{ Frequency of response of experienced feelings } \\
\hline Gender & Motivation & Satisfaction & Realization & Happiness & Frustration \\
Female & 11 & 8 & 7 & 11 & 9 \\
Male & 48 & 37 & 22 & 42 & 11 \\
\hline
\end{tabular}

The feeling that greater experienced male students, was the motivation with a frequency of 48 , while in the case of women registered equal frequency in motivation and happiness. The men showed a frequency of 42 in happiness. The survey was conducted after the award ceremony, it was not really studied because it is more frustrating for women.

In summary, we can see that in women there is a frequency of $24 \%$ of frustration against a $76 \%$ of positive feelings (motivation, satisfaction, fulfillment, happiness). And in the case of men, frustration is lower by $7 \%$, while satisfaction is $93 \%$.

Table 3: Achievements obtained by students

\begin{tabular}{|c|c|c|c|c|c|}
\hline \multicolumn{6}{|c|}{ Frequency } \\
\hline Gender & $\begin{array}{c}\text { Assertive } \\
\text { decision } \\
\text { making }\end{array}$ & $\begin{array}{c}\text { Assertive } \\
\text { communicati } \\
\text { on }\end{array}$ & Problem solving & $\begin{array}{c}\text { Group } \\
\text { pressure }\end{array}$ & $\begin{array}{l}\text { Critical } \\
\text { thinking }\end{array}$ \\
\hline Female & 6 & 7 & 12 & 8 & 8 \\
\hline Male & 24 & 32 & 41 & 21 & 26 \\
\hline
\end{tabular}

As shown in Table 3, in the case of women $70 \%$ and men $69 \%$, it is shown as a major achievement the resolution of problems, while the lowest achievement recorded in the case of women is making assertive decisions 35\% and in the case of men it is the Group Pressure 54\%. With these data, it is noted that the group pressure is greater in the case of women than in men. This variable should be considered in future workshops.

Table 4: Other achievements obtained by students

\begin{tabular}{cccccc}
\hline \multicolumn{5}{c}{ Frecuencia } \\
\hline Gender & $\begin{array}{c}\text { Managing } \\
\text { Stress }\end{array}$ & $\begin{array}{c}\text { Self } \\
\text { Esteem }\end{array}$ & Self-knowledge & & \\
Female & 9 & 7 & 8 & 4 & Managing emotions \\
Male & 39 & 14 & 21 & 20 & 9 \\
\hline
\end{tabular}

- Stress is noted as a lower weight element in the case of women (52\%), while with men it is recorded $66 \%$, however in both cases it is greater than $50 \%$, which indicates that there is a good handling by the sample. The lowest indicators in women is the management of emotions with $23 \%$ and in the case of men it is self-esteem with $23 \%$.

- Would you like to continue with the robotics workshops? Both $100 \%$ of women and men answered yes.

As evidenced in the previous tables, despite the differences in achievements, $100 \%$ of the sample responded that if they like the work done in the workshops. Which indicates in one way or another, that the methodology used is adequate.

- I would invite other schools to participate in robotics courses. Both $100 \%$ of women and men answered yes.

- Would you like to participate more in this type of event? $100 \%$ answered yes. 
Thanks to the motivation of $100 \%$ of the sample, this indicates that it is important to carry out more robotics meetings, which will be taken into account for the future, given that the cooperating entities, for the success obtained, are guaranteed to expand the project and the injection of resources to continue.

- When asked why they liked to participate, the following answers were found:

Table 5: Response of female students regarding their participation in the Olympiad

\begin{tabular}{|c|}
\hline Answers of Women \\
\hline Because it's very fun and I like it a \\
lot.
\end{tabular}

In the case of women's responses, about their participation in the event, there is a high motivation component, which includes feeling that the work they do is fun, that they can experiment, work better as a team, allow them to make more effort, make possible to healthy competition, development of attitudes for life, a way to learn better and in general, they like it.

Table 6: Student men's response regarding their participation in the Olympiad

\begin{tabular}{|c|}
\hline Men's response \\
\hline Because it is very attractive and entertaining \\
\hline We learn, observe and compare other robots. \\
\hline We know a lot \\
\hline $\begin{array}{c}\text { Experiences lived, new knowledge, personal } \\
\text { and professional growth }\end{array}$ \\
There is competitiveness \\
\hline $\begin{array}{c}\text { I love knowing more about technology and } \\
\text { knowing what else I can do. }\end{array}$ \\
\hline I like it \\
\hline The more participants participate, the more \\
technological use options are reached. \\
\hline $\begin{array}{c}\text { We can measure ourselves at the national } \\
\text { level and choose more to achieve projects that } \\
\text { attract the attention of others. }\end{array}$ \\
\hline To learn more and more and more \\
\hline To play new things and to improve myself \\
\hline $\begin{array}{c}\text { Because in these events you learn a lot from } \\
\text { others. }\end{array}$ \\
\hline Because it is participatory a lot \\
\hline Because it is an opportunity to develop my \\
robotics skills.
\end{tabular}


It is evident that the work in the robotics workshops generates a high motivation component, which is evident in what the students show: that it is very attractive and entertaining and that they learn and this can be through observation and comparison. They get experience, new knowledge, allows interaction with other people, is new and exciting, these and other motivation phrases, make us reflect on the importance of innovation in the classroom, the imperative need of every teacher to find new ways to engage the interest of their students through the use of technological elements. These elements make boys and girls invest their time in positive activities, which allow them to have new opportunities and learning experiences.

The answers obtained in both table 4 and table 5 show how motivated students are to participate in challenges like these and how these types of activities mark them positively in their lives.

\section{Recommendations}

- It is important to have a space for young people to develop their creativity in their schools. Currently, having spaces such as workshops for young people to participate develop skills such as group work and leadership. Therefore, it is recommended within the educational center to provide adequate work spaces.

- It is important to maintain the interest of each teacher in this project and be able to maintain enthusiasm in young people. So the use of social networks has allowed the exchange of knowledge between teachers of different institutions.

- It is recommended that the students who until now have been trained for the future become assistant students of the teachers, to achieve peer learning. And that they themselves develop the ability to share and transmit knowledge.

- Generate spaces for students to meet at least once a year for a meeting or robotics Olympiad.

- According to the indicators of the survey, it is recommended to carry out a deeper analysis, which allows identifying the negative levels and generating intervention protocols to improve these levels.

- Development of new challenges, to motivate and improve creativity in solving problems, as well as raising the level gradually in some challenges of the Olympiad.

- $\quad$ The Motivation and Learning Strategies questionnaire -MSLQ (Motivated Strategies for Learning Questionaire -MSLQ), originally designed by Pintrich [19], is a self-reporting instrument that has been used in research to evaluate motivation and beliefs of students, among other aspects.

\section{Conclusions}

- This type of activities generates a lot of motivation from the participants, both teachers and students, including one of the teams that participated in the meeting, was motivated and participated in the WRO Olympics 2017 in Costa Rica.

- On the other hand, it has generated motivation among the teachers by holding mini-tournaments within the schools as inter-school activities and presentations to the student community.

- In addition, the students who have participated in the trainings by themselves have determined to carry out their projects of scientific fairs in the area of robotics.

- Students are motivated to see solutions proposed by students from other schools and allows them to improve their creativity.

- Based on the total number of participants, it was possible to have $28 \%$ female participation of students, this allows generating different options for students to be motivated to study in the area of technology later thinking about a career related to the technology.

- Students after participating in this activity feel very satisfied and would like to continue participating in new editions of this Olympiad.

- Independence in the use of technology, teachers who at the beginning indicated that they did not know why they were invited to the workshop because they mentioned that they were not skilled in the use of technology; they managed to design, build and program a robot model completely made by they. 
- This type of activities is an example of the application of "Learning by doing", where students learn, interact with others and when they apply their knowledge learned during practice.

\section{Acknowledgment}

We thank the Costa Rican Institute on Drugs of Costa Rica (ICD) and the Ministry of Public Education of Costa Rica (MEP) in the execution of the Training of Trainers in Robotics Project and in believing in the importance of the Olympiad-Encounter of educational Robotics for students and teachers beneficiaries of the project.

\section{References}

[1] P. Fonseca and I. Hernandez, "Formación de Formadores en Robótica para Colegios en Áreas Vulnerables de Costa Rica. Uso de las TIC para Ayudar a los Jóvenes Costarricenses a Evitar el Consumo de Drogas". XLIII Conferencia Latinoamericana (CLEI), $\mathrm{n}^{\circ}$ DOI 10.1109/CLEI.2017.8226421, pp. 1-7, 2017.

[2] UNICEF, "Desarrollo positivo adolescente en America Latina y Caribe", 2008. [En línea]. Available: https://www.unicef.org/lac/Hoja_de_datos_sobre_adolescentes_Cumbre_uv(1).pdf

[3] J.Rojo, "Contribución de los concursos educativos al aprendizaje.Algunas experiencias", 2014. [En línea]. Available: http://uvadoc.uva.es/bitstream/10324/8007/1/TFM-G374.pdf

[4] V.Ruiz, "Innovación en el aprendizaje de las ciencias y la tecnología", Educatrónica, 2007.

[5] A.Zabala, "Cómo aprender y enseñar competencias", Barcelona: Editorial Graó, 2007.

[6] T. Balch and J.Summet, "Designing personal robots for education: hardware, software, and curriculum", Designing personal robots for education: hardware, software, and curriculum, pp. 5-9, 2008.

[7] O.Mubin and C.Bartneck, "Improving speech recognition with the robot interaction language", Disruptive Science and Technology, pp. 79-88, 2012.

[8] W.Church, "Physics with robotics: using lego mindstorms in high school education", Conference in Educational Robotics and Beyond, Proc. Advancement of Artificial Intelligence Spring Symposium, Stanford, 2010.

[9] A.Hirst, J. Johnson, M.Petre and B.Price, "What is the best programming enviroment/language for teaching robotics using lego mindstorms", Artificial Live and Robotics, p.124-131, 2003.

[10] D. Londoño, "La Implementación De La Tecnología Educativa En Los Procesos De Aprendizaje En Primaria", Universidad Católica De Manizales Facultad De Educación Licenciatura En Tecnología E Informática La Robótica Educativa, 2018.

[11] M.Tellez, "Incursión de la Robótica en la Educación", Revista Boliviana. Available:http://www.revistasbolivianas.org.bo/pdf/rit/v4n2/v4n2_a07.pdf, 2016

[12] Olimpiadas Nacionales WRO Costa Rica 2018, Available http://www.wrocostarica.org/

[13] L.Ortíz, En 10 años los robots caminarán entre nosotros , Periodico Campus (2013) Available: http://www.campus.una.ac.cr/ediciones/2013/setiembre/2013setiembre_pag05.html

[14] P. Fonseca and I. Hernandez, " Ejemplo de la incursión de las mujeres en la robótica La experiencia en el proyecto Proyecto Formación de Formadores en Robótica para Colegios en áreas Vulnerables de Costa Rica". XLIII Conferencia Latinoamericana (CLEI, 2017).

Available:http://www.clei201746jaiio.sadio.org.ar/sites/default/files/Mem/LAWCC/lawcc-13.pdf

[15] N.Pujades, La importancia de la Programación en Latinoamerica, Scratch School. (2018). Available: https://www.scratch.school/aprender/importancia-programacion-latinoamerica/

[16] S. Abarca. Psicología de la motivación. San José, C.R.: Editorial UniversidadEstatal a Distancia. (1995). 
[17] W.McWhorter and B.O'Connor,Do Lego Mindstorms motivate students in CS1?, Proceedings of the 40th ACM technical symposium on Computer science education. Pages 438-442, Texas A\&M University - Commerce, Commerce, TX, USA. (2009)

[18] P. Fonseca and I. Hernandez ,"Creación de APP para control de robot con Lego EV3". EduQ@2017 VII Congreso Virtual Iberoamericano de Calidad en Educación Virtual y a Distancia, 2017.

[19] Pintrich, P., Smith, D., García, T. \& McKeachie, W.(1993). Reliability and Predictive Validity of the Motivated Strategies for Learning Questionnaire (MSLQ). Educational and Psychological Measurement, 53 (3), pp.801-813. 